\title{
A Study on Westerly Troughs Near Japan (I)
}

\author{
by \\ S. Ooi, S. Matsumoto and H. Itoo \\ Meteorological Research Institute \\ (Received July 16, 1951)
}

\begin{abstract}
Vertical structure of upper westerly trough near Japan in January 1950 is investigated. Movement of tropopause, inversion layer and cold front, and variation of temperature are inspected. Attentions are paid especially to variation of stratification, distribution of solenoid field, convergence and divergence. The remarkable temperature variation in upper trough may be explained by vertical motion.
\end{abstract}

\section{Introduction}

PALIIEN E., NAGLER K. [1] and many other authors have studied the upper westerlies. It is expected that the upper westerlies may control the behaviors of cyclones and other phenomena in lower atmosphere as is said by BERGGREN R. [2]. Our research aims to study the relations between upper westerly troughs and cyclones. In this report the manners and variations of vertical stratification will be studied systematically, and characteristics common to each trough will. be studied in detail. In section 2 the general situation in January 1950 is stated, using mean N-S cross section and time section. In Section 3 the pressure and temperature pattern is studied and upper troughs are defined. In Section 4 vertical structure of trough is studied, using $\mathrm{N}-\mathrm{S}$ cross section. In Section 5 the variation of vertical structure is studied, and vertical distribution of divergence and convergence is researched using a new quantity $\partial \theta / \partial p$. Vertical distribution of solenoidal field is also studied.

The period used in this report is January 1950, when the precision of upper data is somewhat increased, and the data are taken from Aerological Data of Japan. The area is limited to the Japan islands. Lack of observations, especially of wind, causes considerable difficulties. As the ordinate of our cross section is a logarithmic pressure scale, the length, corresponding to unit height difference, at $100 \mathrm{mb}$ is 1.6 times as large as that at $1,000 \mathrm{mb}$. Tropopause is shown by chain line, connecting the minimum temperature, along isentropic line [3], [4], [5]. The double heavy black lines show lower fronts and upper inversion layers. The latter correspond to what is called Principal Frontal Layer or I'olar Front by PALMIEN E. and NAGLER K. [1]. We call them simply rnversion. Layer, for fear of confusing with BJERKNES' Polur Front. The region between these two heavy black lines is a layer of inversion, equal temperature or nearly equal (smaller than $1^{\circ} \mathrm{C}$ difference) temperature. 


\section{General situation}

Fig. 1 shows the mean state of January 1950. Southern trcjopause extends to $42^{\circ} \mathrm{N}$ from the south at the height of $100 \mathrm{mb}$ or about $17 \mathrm{~km}$ along isentropic line of $420^{\circ} \mathrm{K}$. Northern tropopause extends to $41^{\circ} \mathrm{N}$ from the north at the height of $300 \mathrm{mb}$ or about

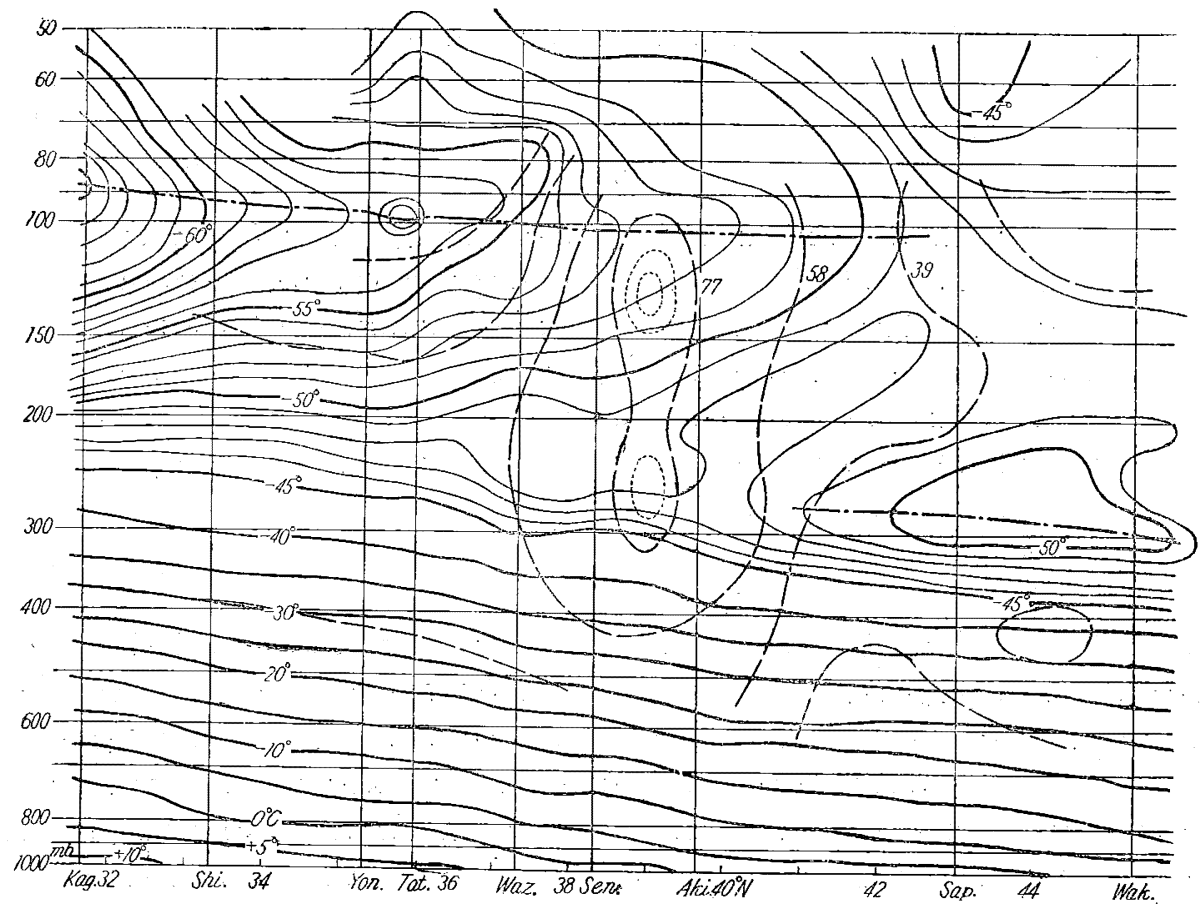

Fig. 1 Mean cross section of $\mathrm{Jan}$. 1950. Abscissa is latitude. Ordinate is logarithm of pressure. Solid lines are isotherıns in $5^{\circ} \mathrm{C}$ or $1^{\circ} \mathrm{C}$ intervals, broken lines isovels, chain lines tropopause.

$9 \mathrm{~km}$ along isentropic line of $330^{\circ} \mathrm{K}$. Temperature gradient in isobaric surface is warmer to the north above $200 \mathrm{mb}$ level, and is colder to the north under $200 \mathrm{mb}$ leve1. All isotherms warmer than $-47^{\circ} \mathrm{C}$ run parallel, inclining northward..' The isotherm of $-48^{\circ} \mathrm{C}$ penetrates into the region between the two tropopauses and indicates a

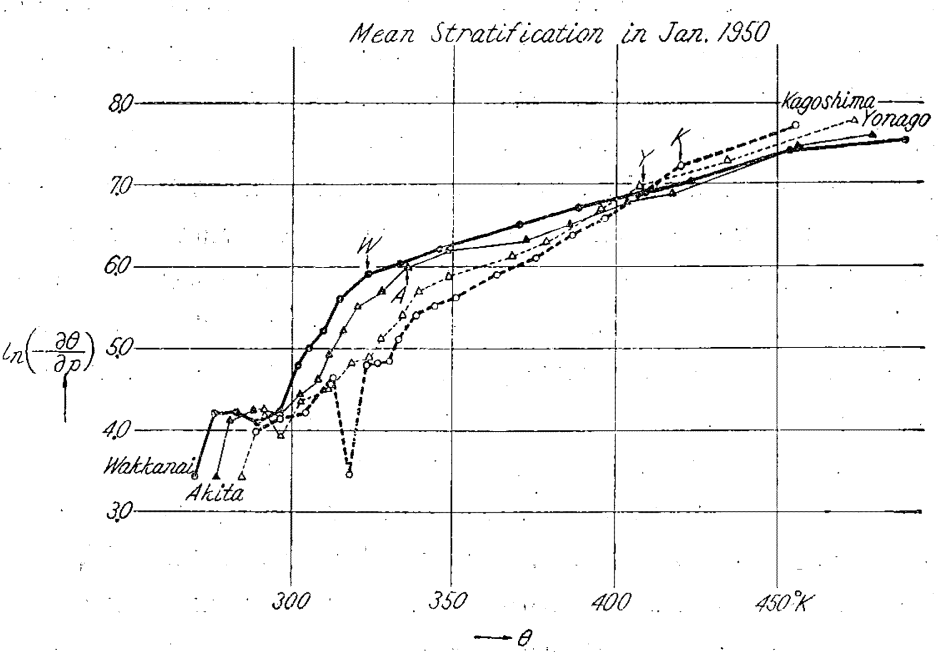

Fig. 2 Mean stratification in Jan. 1950. (See Fig. 18 for explanation of diagram) 
warmer region. To the south of this region, there is also a region of small lapse rate, which is the starting point of inversion layer. At the southern latitude, as the inversion layer changes its height, the region of small lapse rate does not appear. Broken lines are isovels of 77, 58 and $39 \mathrm{~m} / \mathrm{sec}$ and show two maxima at $39^{\circ} \mathrm{N}$ on 125 and $250 \mathrm{mb}$ levels. These values are obtained by geostrophic wind calculation from north-south gradient of monthly mean pressures.

Fig. 2 shows mean stratification by means of vertical stability $\partial \theta / \partial p$, the meaning of which is stated in Section 5. Full lines are of stations in northern tropopause, and broken lines in southern tropopause. Tropopause levels are shown by arrows. It is noted that the state in stratosphere above both tropopauses appears as straight lines of same inclination in this figure.

Fig. 3 shows the time section of Wakkanai. The northern tropopause at $300 \mathrm{mb}$ is surrounded by $-50^{\circ} \mathrm{C}$ isotherm, and sometimes by $-55^{\circ} \mathrm{C}$ isotherm. The clouds and cold fronts are low in height and rarely reach $600 \mathrm{mb}$ level.

The time section of Sendai is omitted for want of space. It is similar to that of Yonago, but has a character that the southern tropopause comes out in front of trough and the northern tropopause in the rear of trough.

In the time section of Yonago (Fig. 4), a remarkable inversion layer is seen. It runs in the layer between $300 \mathrm{mb}$ and $150 \mathrm{mb}$, and its altitude and thickness changes. It becomes lowest at trough, and highest or vanishes at ridge. For example, on 1 January it is thin and becomes gradually thicker and lower, and at the trough of 6 January it extends between $400 \mathrm{mt}$ and $200 \mathrm{mb}$, and then ascends suddenly to $200 \mathrm{mb}$ level. Isotherms of $-40^{\circ} \mathrm{C}$ and $-50^{\circ} \mathrm{C}$ ascend and descend suddenly at the trough. The isotherm of $-30^{\circ} \mathrm{C}$ runs reversely. Very high cold front, extending to $400 \mathrm{mb}$, is seen at the trough. Namely, the heating and cooling in layers above $400 \mathrm{mb}$ level, cooling in those lower than $400 \mathrm{mb}$ level, descent and ascent of inversion layer, and very high cold front are remarkable characteristics at the trough in this latitude. These characteristics are sean on 6, 10, 15, 20 and 24 January, and these days correspond well to the upper troughs defined in Section 3.

Surface weather maps are omitted for want of space. Former four troughs correspond to the outburst of cold wave. In these periods Siberian High and Okhotsk Low develop remarkably, and face to each other on both sides of Japan Islands, and isobars run north to south, with their maximum gradient. The trough of 20 January differs from the others. Though the situation at the trough is closely similar to that of the others, a large Low develops later over Siberia, Siberian High retreats, and Japan is covered by a zonal high pressure belt.

In the time section of Kagoshima (Fig. 5), tropopause is surrounded by $-70^{\circ} \mathrm{C}$ isotherm. The inversion layer is thin and sometimes disappears, and its altitude is far lower than that of Yonago and runs in the layer between 400 and $200 \mathrm{mb}$ levels. The time section has almost similar characteristics to those of Yonago. Cold fronts are low and do not reach $600 \mathrm{mb}$ level, their transition layer is thin in front of them, and very thick in rear of it, showing strong inversion. 


\section{Time sections of temperature and height in pressure levels and charac- teristics of solenoid number}

As the observations used are confined within the narrow Japan Islands, we have no reliable upper weather charts. Hence time sections of temperature and height of several standard pressure levels, that is, $700 \mathrm{mb}, 500 \mathrm{mb}, 300 \mathrm{mb}$ and $200 \mathrm{mb}$, are presented in Fig. 6. These time sections are used to define upper troughs instead of upper weather charts.

Contour lines (solid lines) at each standard pressure level show nearly wavelike undulations, and neglecting small undulations, five troughs are found on about $6,10,15,20$ and 24 January. Besides, smaller troughs are found on about 4 and 29 January, but their durations are brief and minimum values of pressure are not so small. Therefore, in our analysis five developed troughs are studied in detail.

The last of five troughs keeps the feature of trough during a longer period on account of either slow movement or long wave length. This appears as a difference on surface weather maps. That is already said in Section 2.

Isotherms (broken line) at $700 \mathrm{mb}$ and $500 \mathrm{mb}$ run almost in parallel to contour: lines. It is seen from Figs. 6 (a) and 6 (b) that the layer under $500 \mathrm{mb}$ is occupied with cold air during the periods of troughs and with warm air during those of ridges. Fig. 6.(c) shows that at $300 \mathrm{mb}$ warm air appears in front of trough. This disposition is remarkabe at the trough of 6, 20 and 24 January. Fig. 6 (d), timesaction at $200 \mathrm{mb}$, shows alternation of warm and cold air. Roughly speaking, it is warm in front of trough and is cold in rear of trough and at ridge (at $200 \mathrm{mb}$ ). On the other hand, in the lower layer, $500 \mathrm{mb}$ or $700 \mathrm{mb}$, it is warm at ridges and is cold at troughs. The characteristic properties of stratification at each trough are more precisely studied in following sections.

Next, variation of horizontal solenoid is studied. The vorticity equation is

$$
\frac{d Z}{d t}+Z Q=R\left(\frac{\partial T}{\partial y} \frac{\partial \ln p}{\partial x}-\frac{\partial T}{\partial x} \frac{\partial \ln p}{\partial y}\right) \equiv N,
$$

where $Z$ is a vertical component of absolute vorticity, $Q$ horizontal divergence and $N$ horizontal solenoid number. $N$ in equation (1) is rewritten as follows,

$$
N=\frac{1}{T}\left\{\left(\frac{\partial T}{\partial y}\right)_{p}\left(\frac{\partial \Phi}{\partial x}\right)_{p}-\left(\frac{\partial T}{\partial x}\right)_{p}\left(\frac{\partial \Phi}{\partial y}\right)_{p}\right\},
$$

where $\phi$ is geopotential and suffix $p$ means differential along an isobaric surface. Horizontal solenoid number, $N$, at $700 \mathrm{mb}, 500 \mathrm{mb}$ and $300 \mathrm{mb}$ are calculated from observations of Wakkanai, Tateno and Yonago by using (2), because our materials are given at the standard pressure levels. The results are shown in Fig. 7. $N$ increases with altitude unexpectedly. But, even the largest is the order of $10^{-10} \mathrm{sec}^{-2}$ and is smaller by one order than that of the left hand side in equation (1), because $Z$ is the order of $10^{-4} \mathrm{sec}^{-1}$ and $Q$ is that of $10^{-5} \mathrm{sec}^{-1}$ in case of our study. It is interesting that solenoid at $700 \mathrm{mb}$ has positive (cyclogenesis) extreme value on 5 , 10 and 15 January when developed cyclones pass along Japan Islands, and the curves at $700 \mathrm{mb}$ and $300 \mathrm{mb}$ in Fig. 7 are almost reverse. 


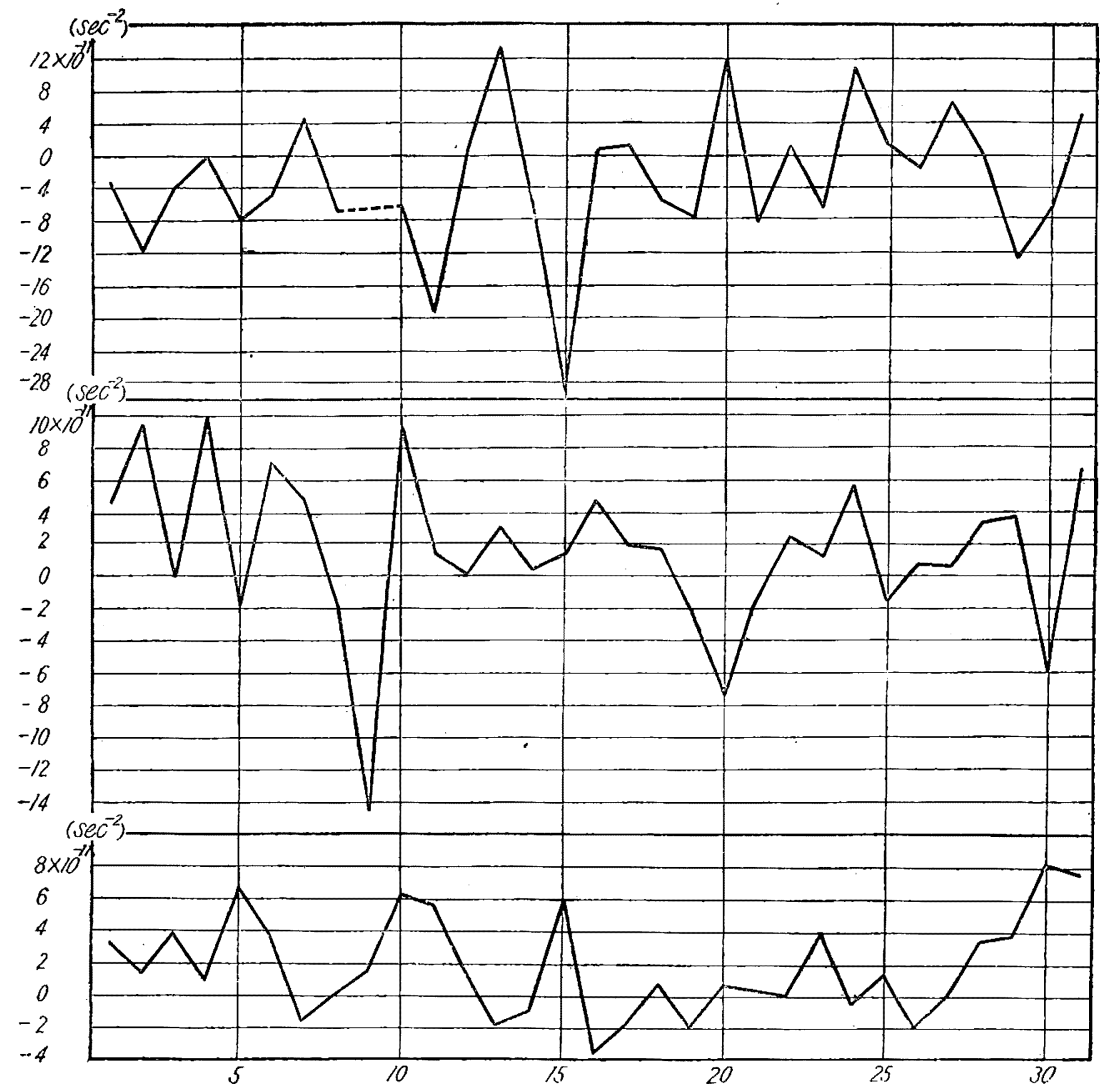

Fig. 7 Daily Solenoid number at $700 \mathrm{mb}, 500 \mathrm{mb}$ and $300 \mathrm{mb}$ in Jan. 1950.

\section{Cross sections o $f$ trough}

By the analysis of the pressure pattern in Section 3, five troughs are defined. By the ana ysis in December 1949 also fivet roughs are defined. But details of the latter are omitted in this report. These ten troughs had similar structure, and the trough of 6 January is studied as the typical one, in this and subsequent sections. A strong cycione that passed on 6 to the north of Akita and Siberian High and Okhotsk Low attained their maximum developments (Fig. 8). As is seen in Fig. 5 the layer above $400 \mathrm{mb}$ level becomes very warm in front of the trough and very cold in rear of it.

Fig. 9 shows the state in front of the trough. The two tropopauses are at their mcan positions in Fig. 1. From the warm region the inversion layer starts, and runs inclining to the south, and reaches $600 \mathrm{mb}$ at Shionomisaki. The variation in altitude of the inversion layer is shown in Fig. 5. The wind is $W S W 110 \mathrm{~m} / \mathrm{sec}$ at $150 \mathrm{mb}$ on Shionomisaki, WSW $85 \mathrm{~m} / \mathrm{sec}$ at $260 \mathrm{mb}$ on Tateno, and $W 50 \mathrm{~m} / \mathrm{sec}$ at $300 \mathrm{mb}$ on Sendai. Namely the wind becomes weaker toward the north. The southerly component is seen in the region above the inversion layer.

Fig. 10 shows the state near the center of the trough. A very high cold front 


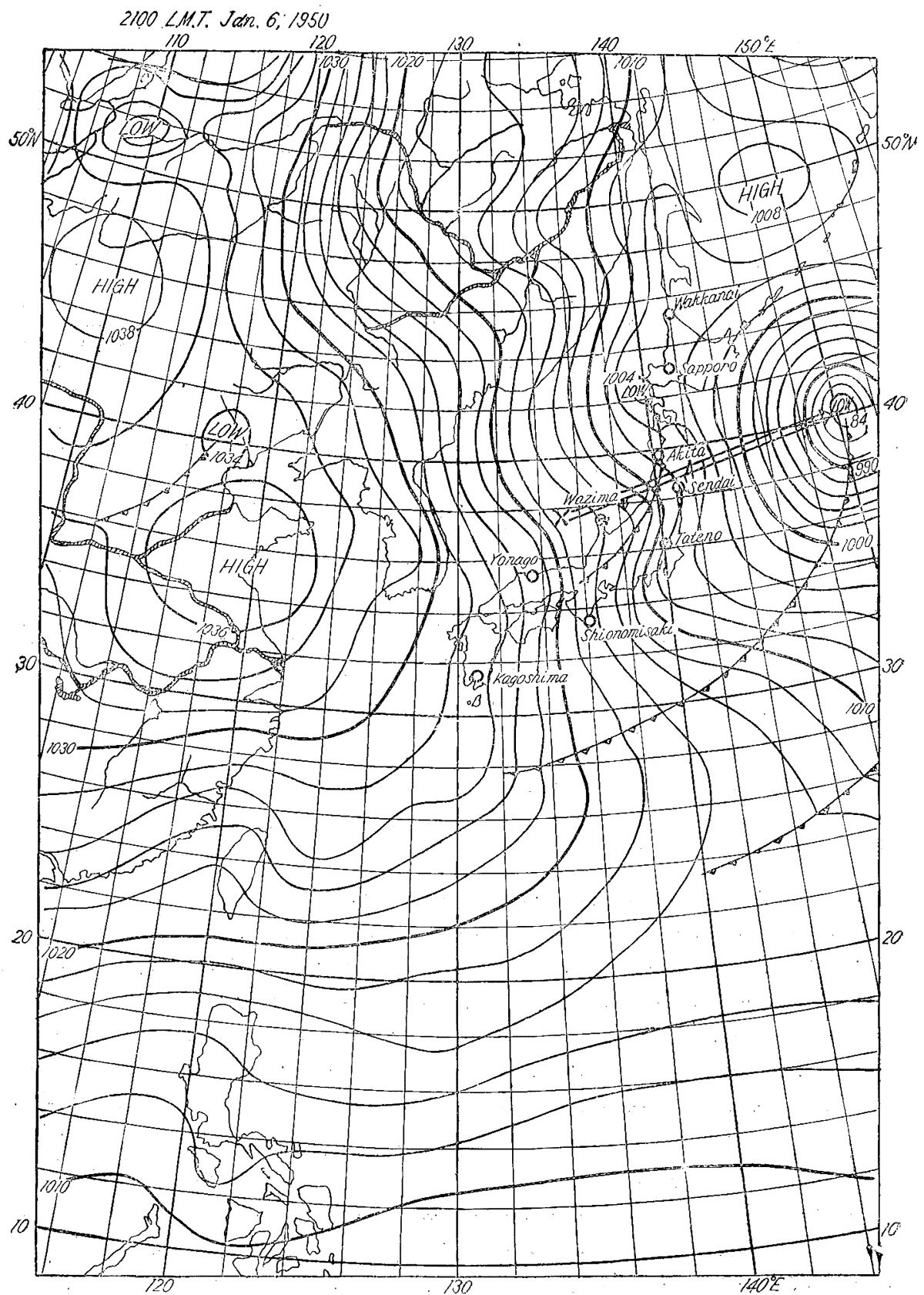

Fig. 8 Surface weather map of 2100 Y.. M.T. Jan. 6, 1950. Isobars are in $2 \mathrm{mb}$ intervals. A cyclone generated over the Japan Sea $24 \mathrm{hrs}$ before develops rapidly from $1010 \mathrm{mb}$ to $984 \mathrm{mb}$, and isobars rum north to south in Japan having maximuin gradient. 


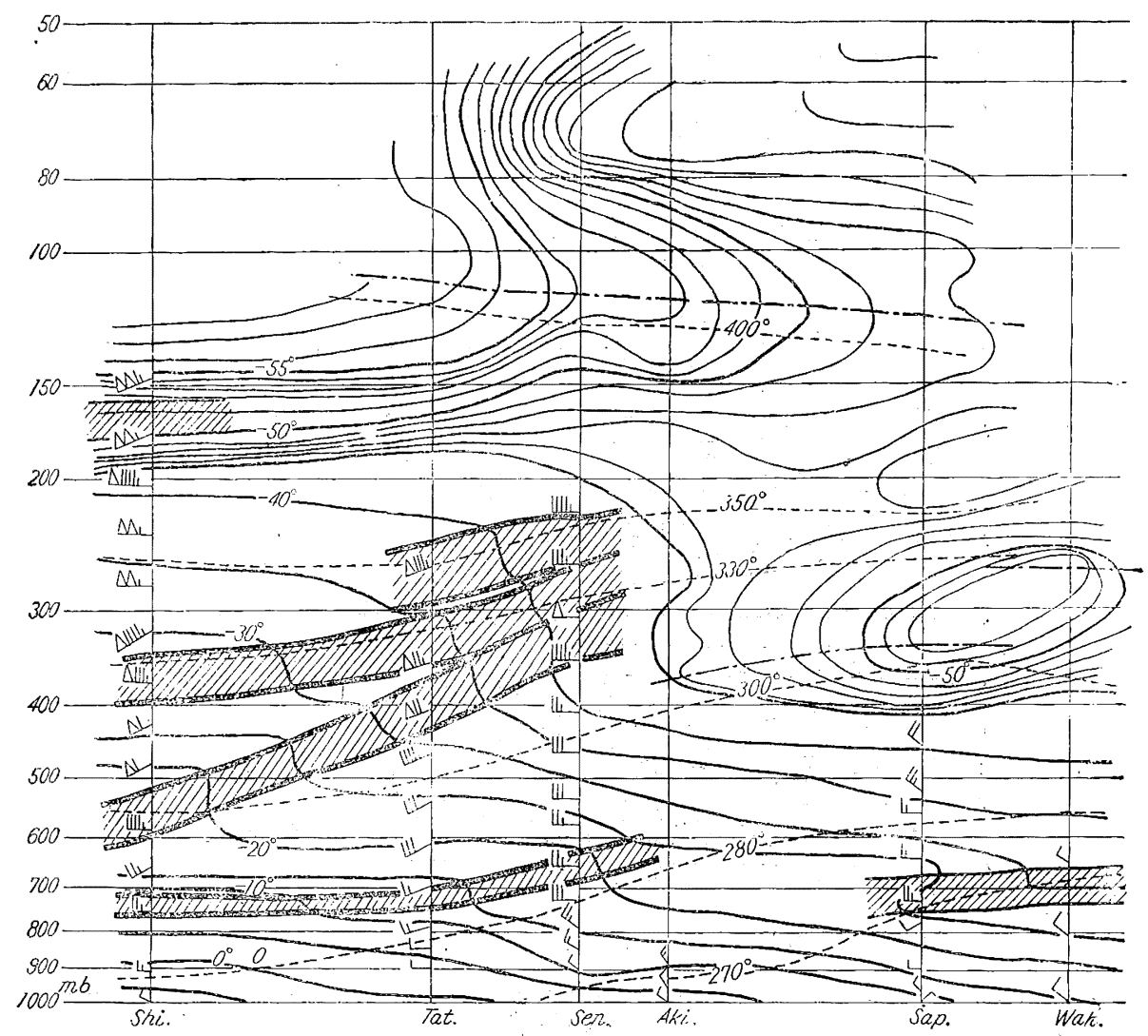

Fig. 9 Cross section at 1200 I.M.T. Jan. 5, 1950. Abscissa is taken proportional to actual distance between stations. N-S cross section betwecn IVakkanai and Shionomisaki, and SW-NE cross section between. Shionomisaki and Kagoshima. Solid lines are isotherıns in $5^{\circ}$ or $1^{\circ} \mathrm{C}$ intervals, broken lines isentropic lines, double heavy solid lines inversion layer or fronts. Wind in $\mathrm{m} \mathrm{sec}^{-1}$ (full barb $10 \mathrm{~m} \mathrm{sec}^{-1}$, triangle $50 \mathrm{~m} \mathrm{sec}^{-1}$ ).

is connected with the northcrn tropopause at $400 \mathrm{mb}$ level. The cold front is accompanied with an intense cyclone to the north of Akita (Fig. 8). The region above $330 \mathrm{mb}$ at Sencai becomes of equal temperature and the inversion layer runs horizontally. A southerly component of wind is seen in the whole region over the cold front. The wind is $W S W 95 \mathrm{~m} / \mathrm{sec}$ at $300 \mathrm{mb}$ on Tateno, and $W S W 102 \mathrm{~m} / \mathrm{sec}$ at $270 \mathrm{mb}$ on Sendai. The wind speed maximum moves to the north as a whote. A high cold front and ascent of the inversion layer are characteristics in this state.

Fig. 11. shows the state in rear of the trough. The cold front becomes lower and separated from tropopause. The northern tropopause extends southward to Shionomisaki. The whole region above the northern tropopause becomes a large warmer area.

From the above analysis following conclusions are obtained.

(1) In front of the trough, two tropopauses are in their mean positions. The 


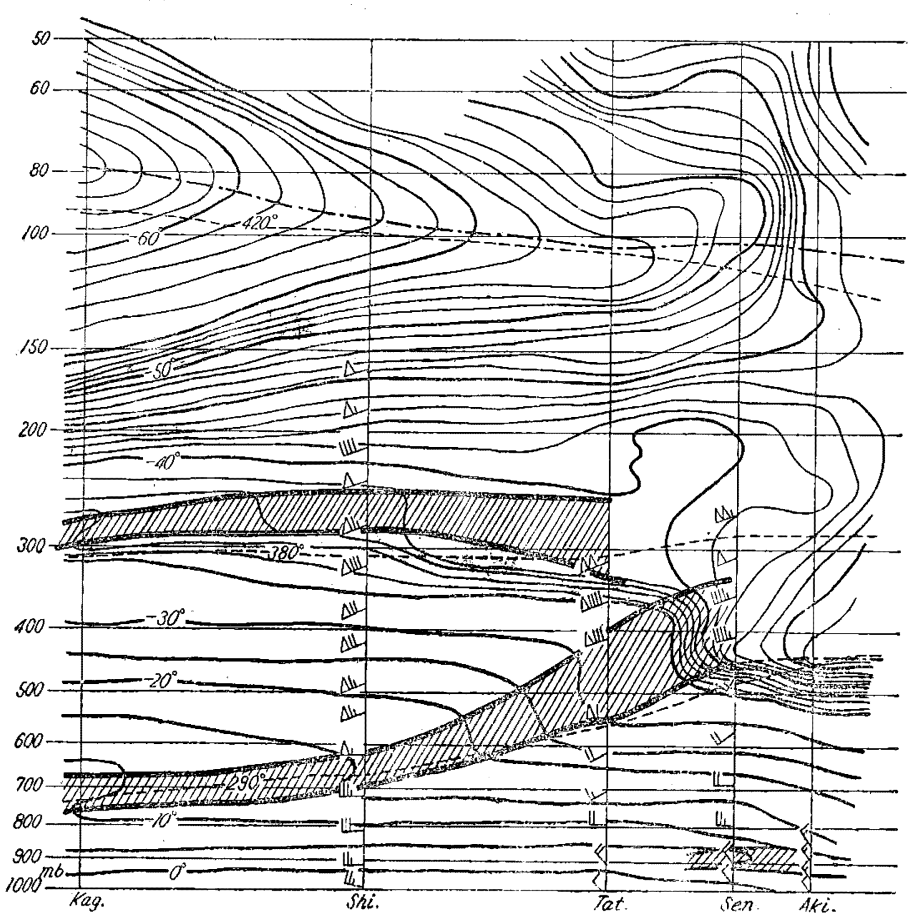

Fig. 10 N-S cross section at 1200 1.. M.T. Ja1. 6, 1950.

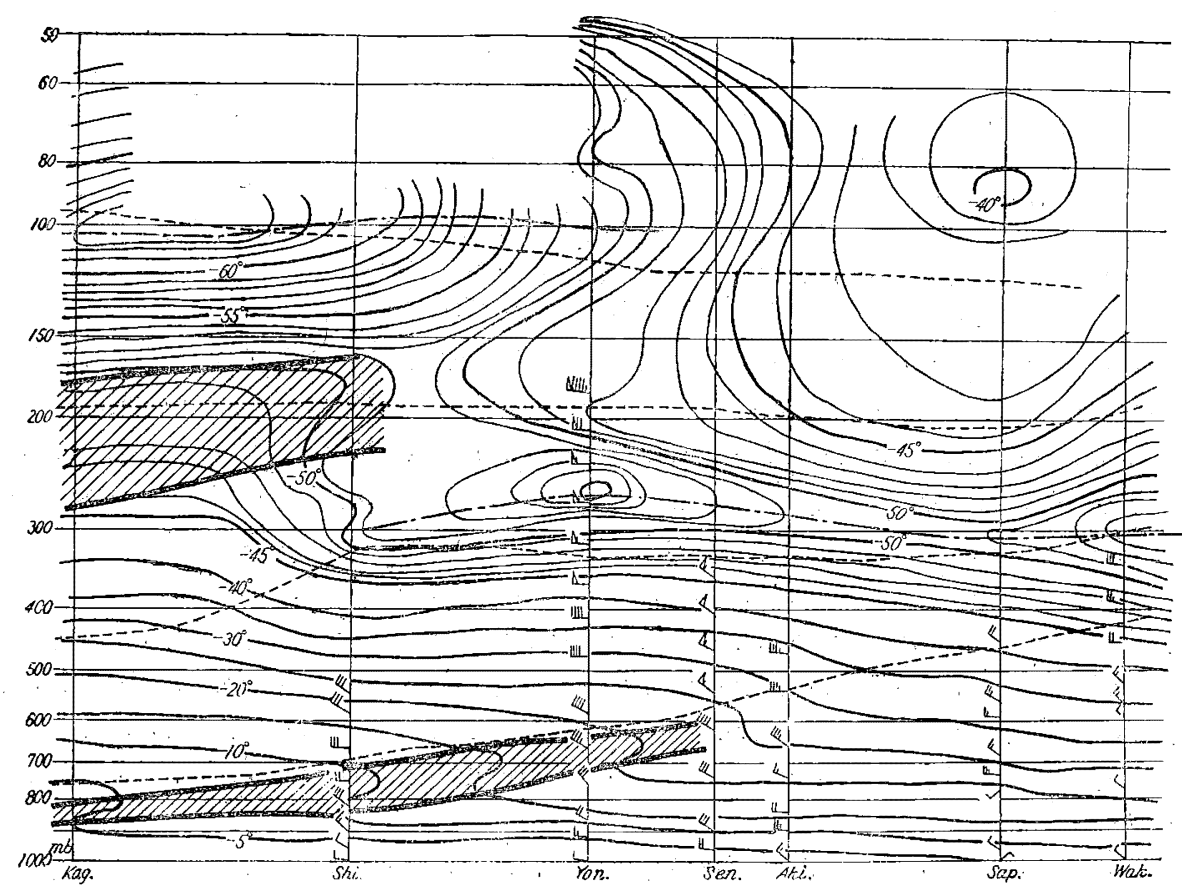

Fig. 11 N-S cross section at 1200 T. M. T. Jan. 7, 1950. 
inversion layer starts from the region between two tropopauses, inclining to south. Above the inversion layer WSW wind blows.

(2) Near the center of trough, a very high cold front is connected with the northern tropopause. The southein part of the inversion layer takes its lowest position. The area above $400 \mathrm{mb}$ level, south of Akita, becomes very warm.

(3) In rear of the trough, the northern tropopause extends to the south, and the southern tropopause retreats. Above the northern tropopause a wide warmer area appears. The region above $400 \mathrm{mb}$ level south of Akita becomes very cold.

\section{Changes in vertical structure}

It is found that temperature variation larger than $20^{\circ} \mathrm{C}$ is the remarkable character of the trough in upper layers $(300 \sim 200 \mathrm{mb})$. This is emphasized in Figs. $12 \sim 14$ by taking the anomaly from mean value of this month. Figs, $12 \sim 14$ are the time sections at stations of various latitudes. These figures show the remarkable feature in which warm and cold areas are systematically distributed. As to Yonago (Fig.13) which was the station nearest to the path of the cyclone, we find a strong cold area under $350 \mathrm{mb}$ level, a strong warm area in $350 \sim 150 \mathrm{mb}$ layer and weak

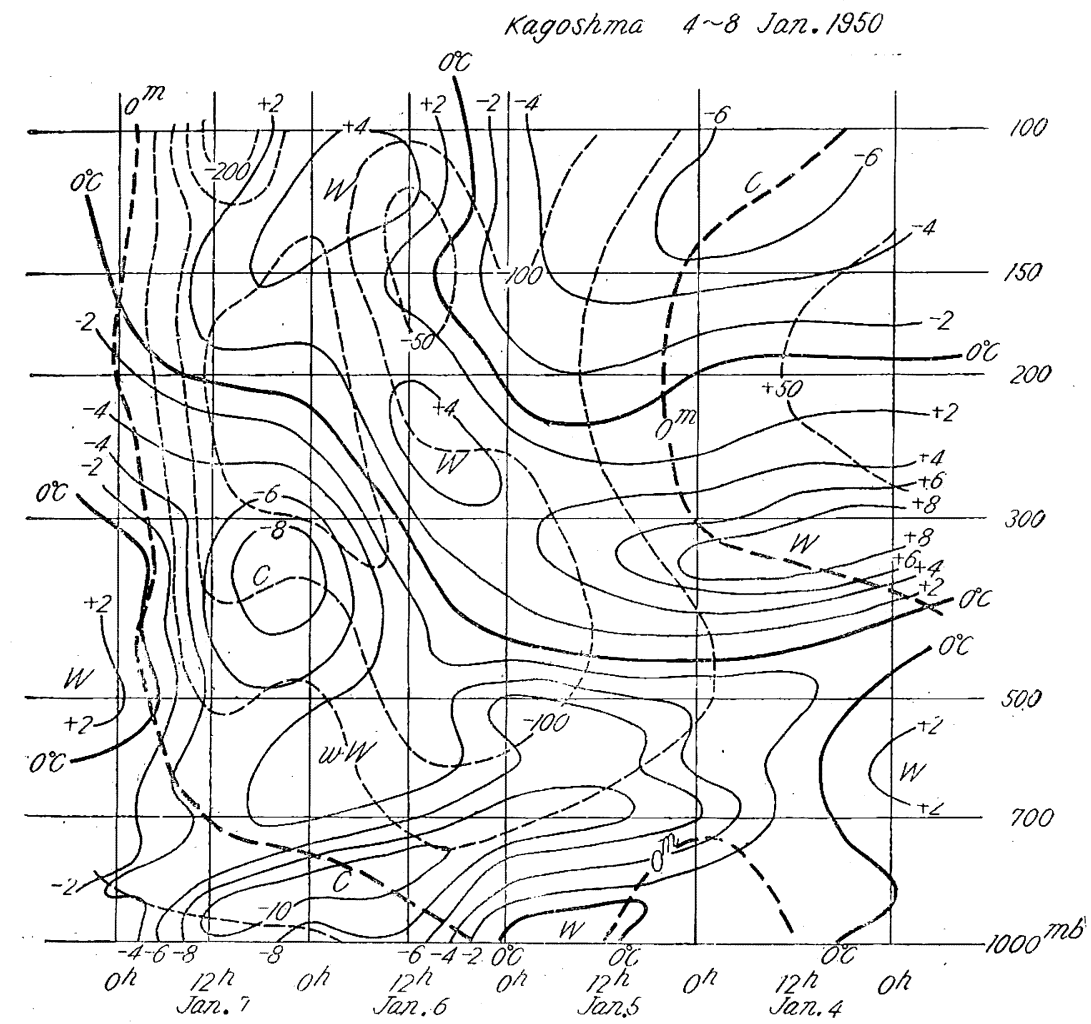

Fig. 12 The time section of temperature and pressure anmaly at Kagoshima during the perior! $4 \sim 8$ Tan. 1950. Full lines show temperature anomaly at every $2^{\circ} \mathrm{O}$. Broken lines show pressure anomaly at every $50 \mathrm{~m}$ in height difference of standard pressune levels. 


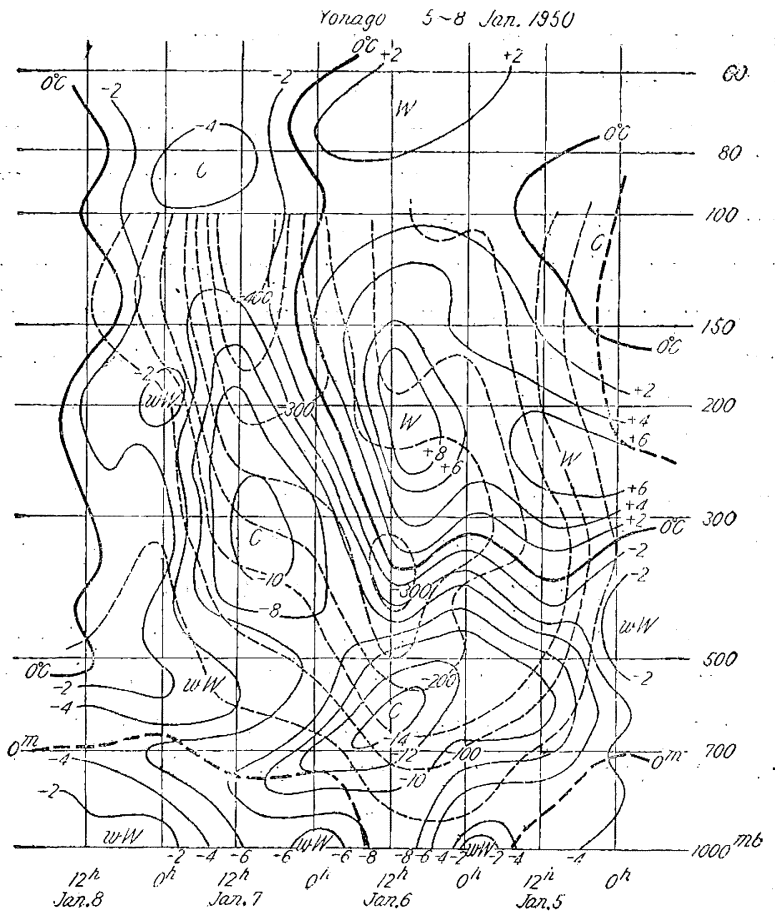

Fig. 13 Same as Fig. 12 at Yonago during the period 5 8 Jan. 1950.

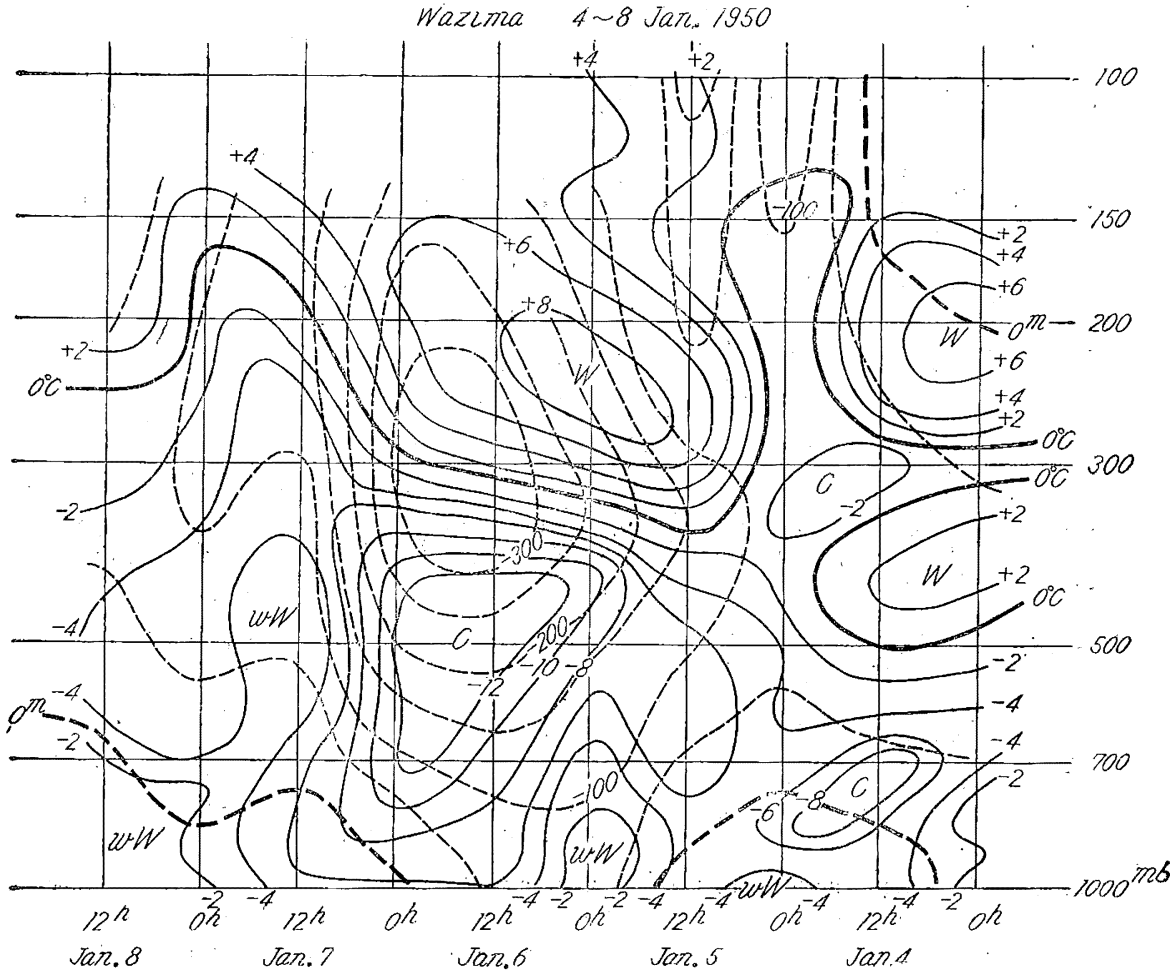

Fig. 14 Same as Fig. 12 at Wazima during the period 4 8 Jan. 1950. 
cold area near $100 \mathrm{mb}$ level in front of the trough, and weak warm area beneath $500 \mathrm{mb}$ level, superior cold area in $500 \sim 150 \mathrm{mb}$ layer and slight warm area near $100 \mathrm{mb}$ level in the rear of the trough. Anomaly of standard pressure level which is shown by broken lines in the figure shows the retardation of minimum pressure in the higher layer which has been remarked as the so-called tilt of cyclone axis [6], [7]. The discrepancy of minimum pressure between lower and higher levels should match with temperature distribution described above, and the low pressure near $100 \mathrm{mb}$ level is masked by cold air beneath and the remarkable warm air in front from $350 \mathrm{mb}$ to $100 \mathrm{mb}$ originates a cyclone on the ground. Figs, 15 17 are cross sections of anomaly and show that the temperature field stated above has a large horizontal extent.

How is this temperature field as the structure of trough built up? What explains this is either horizontal advection or vertical motion. It is seen in Fig. 1 that monthly mean northsouth temperature gradieni: diminishes near $250 \mathrm{mb}$ level and it becomes warmer to

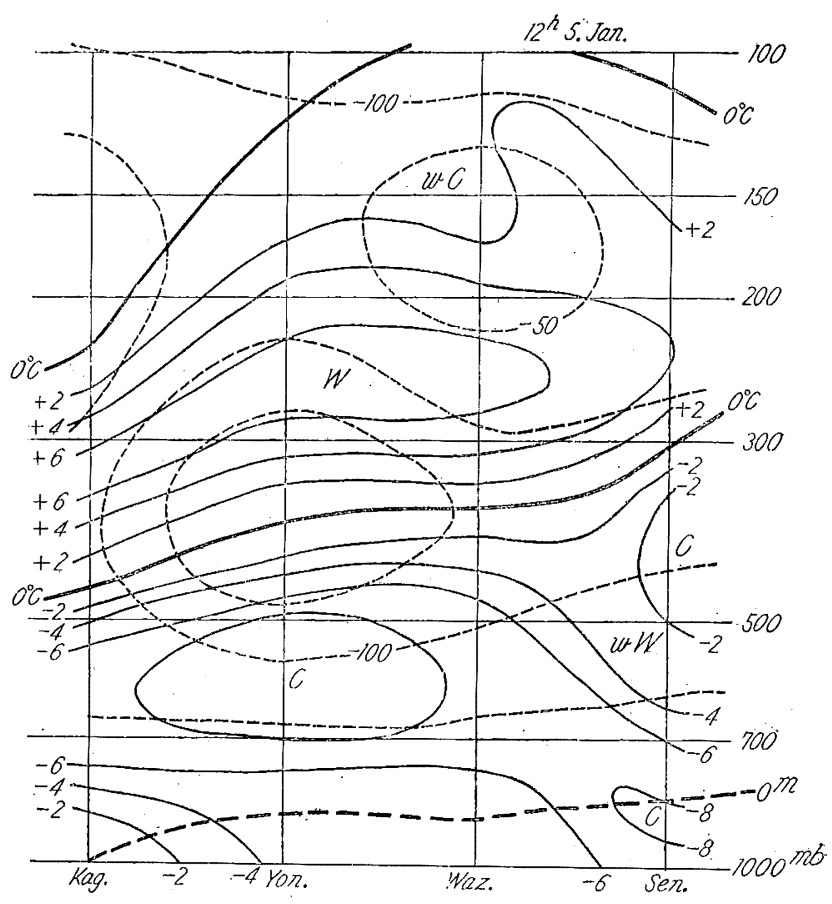

Fig. 15 WSIV-ENE cross section of temperature and pressure anomaly at 1200 I. II. T'. Jau. 5, 1950. Full lines and broken line are same as in Fig. 12 .

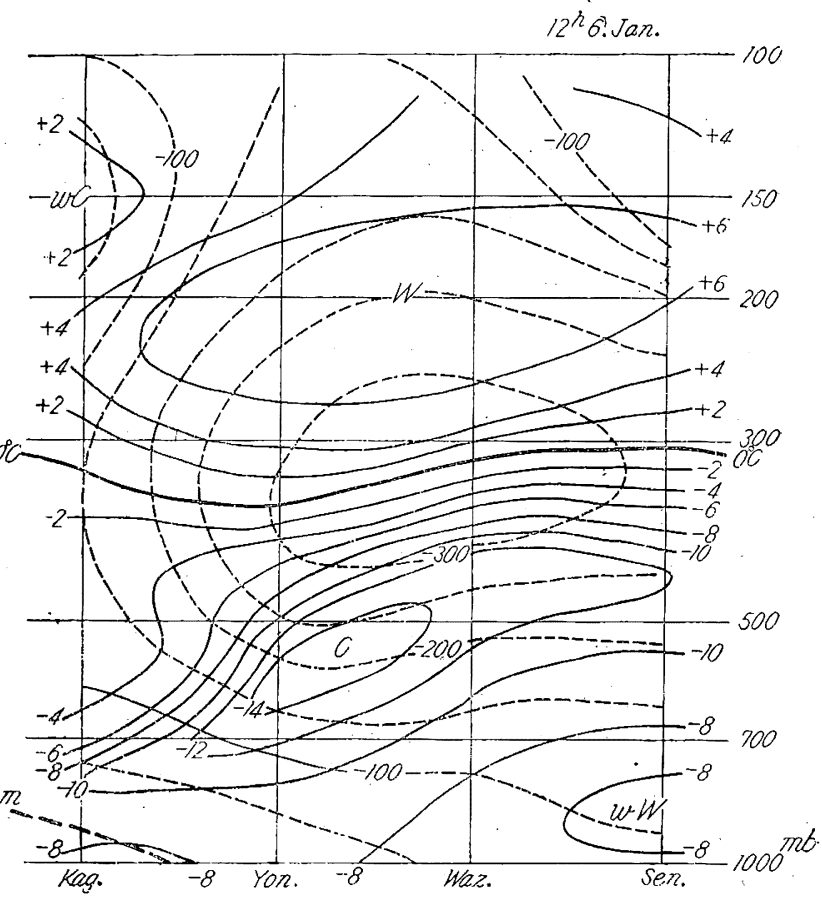

Fig. 16 Same as Fig. 15 at 1200 L. M. T. Jan. 6, 1950. 


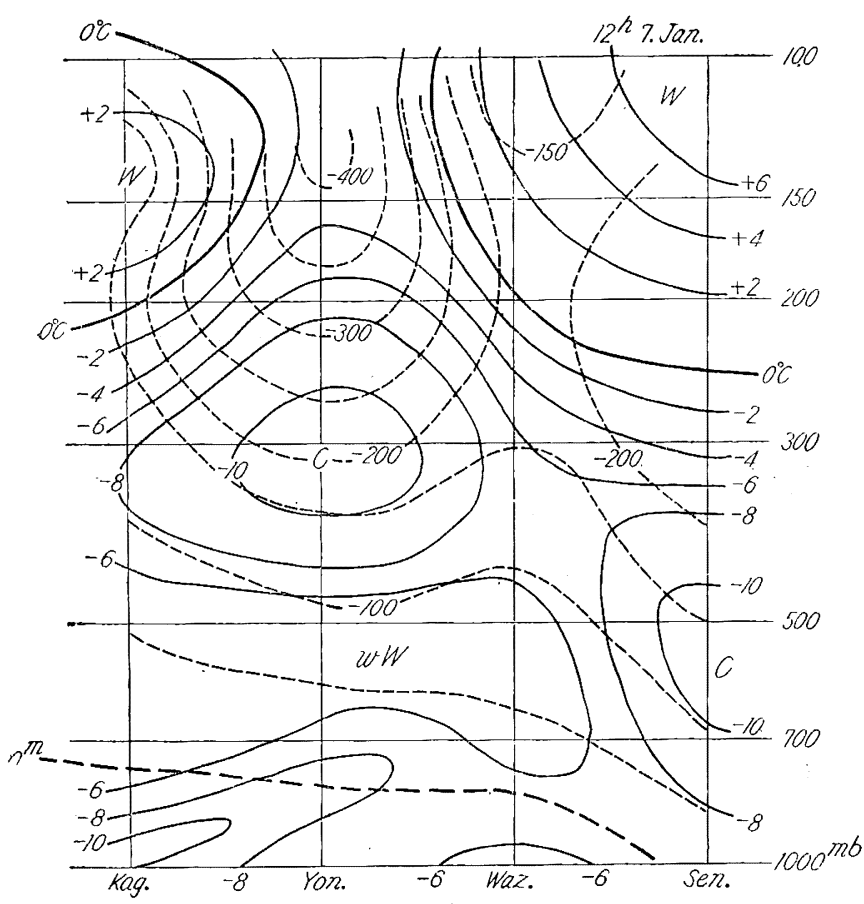

Fig. 17 Same as Fig. 15 at 1200 I. M.T. Jan. 7, 1950 the north and cooler to the south above it. Therefore we can not find anything like a cold source or warm source in the layer near $250 \mathrm{mb}$ level, and besides, we cannot obtain sufficient data to determine hori onta! avection in our region. We intend to explain by vertical motion. One of the writers [8]. introduced the following equation combining the equation of continuity and that of conservation of $\theta$ (we use potential temperature).

$$
\begin{aligned}
& \text { (3) } \frac{d}{d t} \ln \left(-\frac{\partial \theta}{\partial p}\right) \\
& =\operatorname{div}_{2} v+\frac{\partial u}{\partial z}\left(\frac{\partial z}{\partial x}\right)_{0}+\frac{\partial v}{\partial z}\left(\frac{\partial z}{\partial y}\right)_{0},
\end{aligned}
$$

where $\frac{\partial \theta}{\partial p} \equiv \frac{\partial \theta}{\partial z} / \frac{\partial p}{\partial z}$ and corresponds to vertical stability, $\left(\frac{\partial z}{\partial x}\right)_{\theta}$ and $\left(\frac{\partial z}{\partial y}\right)_{\theta}$ indicate the inclination of isentropic surface.

The last two terms are neglected against the first on the right hand side for large scale motion. Therefore the above equation expresses that individual change of $\ln \left(-\frac{\partial \theta}{\partial p}\right)$ is caused by hori ontal divergence div: $\boldsymbol{v}$. The change of vertical stratification is investigated on Figs. 18 20 by taking $\ln \left(-\frac{\partial \theta}{\partial p}\right)$ for ordinate and $\theta$ for abscissa (corresponding to altitude). Fig. 18 shows the change in front of the trough on which the state in Yonago at 1200 L.M.T. 5 January is compared with the states in three stations (Yonago as the middle) 12 hours before. This figure shows that the vertical stability over Yonago at 1200 L.M.T. 5 January decreases in the layers whose potential temperature is from $270^{\circ} \mathrm{K}$ to $280^{\circ} \mathrm{K}$ and

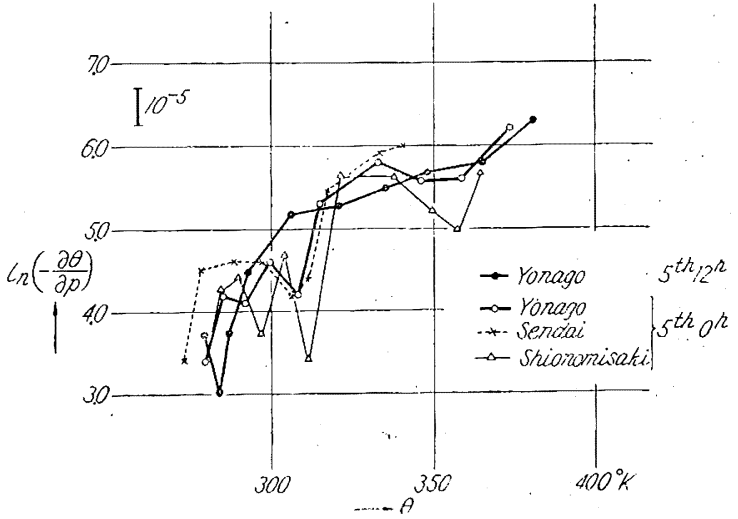

Fig. 18 The change of vertical stratification from 0000 to 1200 I. M.'T. Jan. 5, 1950. Potential temperature for abscissa, $\ln \left(-\frac{\partial \theta}{\partial p}\right)$ for ordinate. 
from $320^{\circ} \mathrm{K}$ to $350^{\circ} \mathrm{K}$ and increases in the layer from $290^{\circ} \mathrm{K}$ to $320^{\circ} \mathrm{K}$ whether the air came from the north or the south. In other words there was divergence in the middle layer about $500 \mathrm{mb}$ level and convergence in the layers above and beneath it. In the same manner Fig. 19 shows the change in rear of the trough. The air column over Yonago at 0000 L.M.T. 7 January is composed after the effect of convergence in the middle layer about $500 \mathrm{mb}$ level and divergence in the layers above and beneath it. These phenomena occurred at the same time in Kagoshima, Yonago and Sendai (Fig. 20) and therefore it may be concluded that the temperature field mentioned above resulted from largescale vertical motion.

If the trajectory of air particle is known, we can estimate $\operatorname{div}_{z} \boldsymbol{v}$ quantitatively, but unfortunately upper wind observation is not sufficient in number and accuracy, But we recognized from Figs. 18 and 19 that we

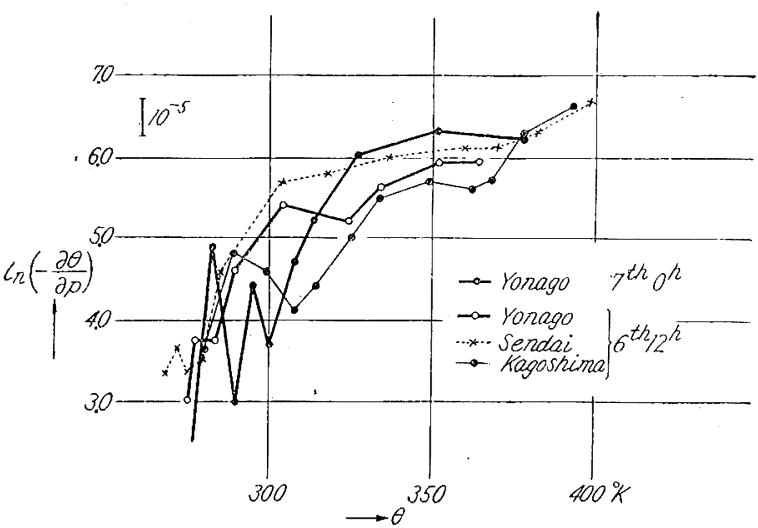

Fig. 19 The change of vertical stratification from 1200 I.M.T. Jan. 6 to 0000 I..M.T. Jan. 7, 1950.

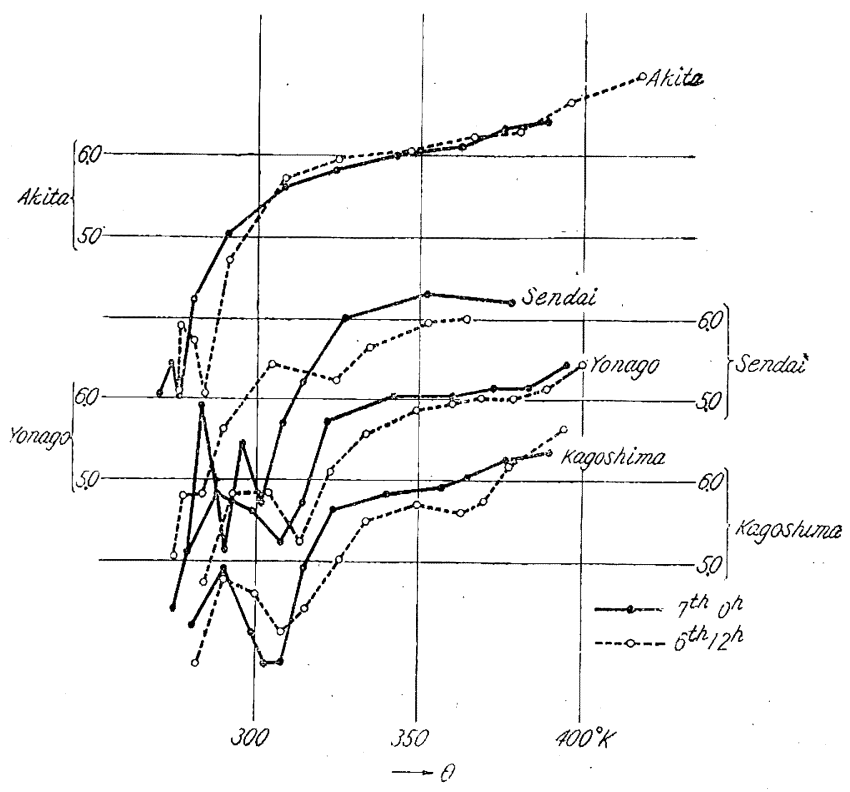

Fig. 20 Same as Fig. 18. Heary black lines show the state at. 0000 I. M. T. Tan. 7, and double lines show the state 12 hours before at every stations.

never mistake the sense of variation from conventiona! calculation by one-point observation, and so we perform quantitative calculation using twice-a-day observation at Yonago. The result is shown on Fig. 21. The area of divergence or convergence over $10^{-5} \mathrm{sec}^{-1}$ is represented by thin solid line. The vertical motion expected from the distribution of divergence and convergence in Fig. 21 is of the order $1 \mathrm{~cm} / \mathrm{sec}$ and sufficient to explain the temperature field in Fig. 13. The schematic feature of vertical motion is illustrated in Fig. 21. The region of ascending motion under $\$ .00 \mathrm{mb}$ level corresponds to cold area and that of descending motion to warm area 
in front of the trough, and the region of descending motion under $500 \mathrm{mb}$ level corres-

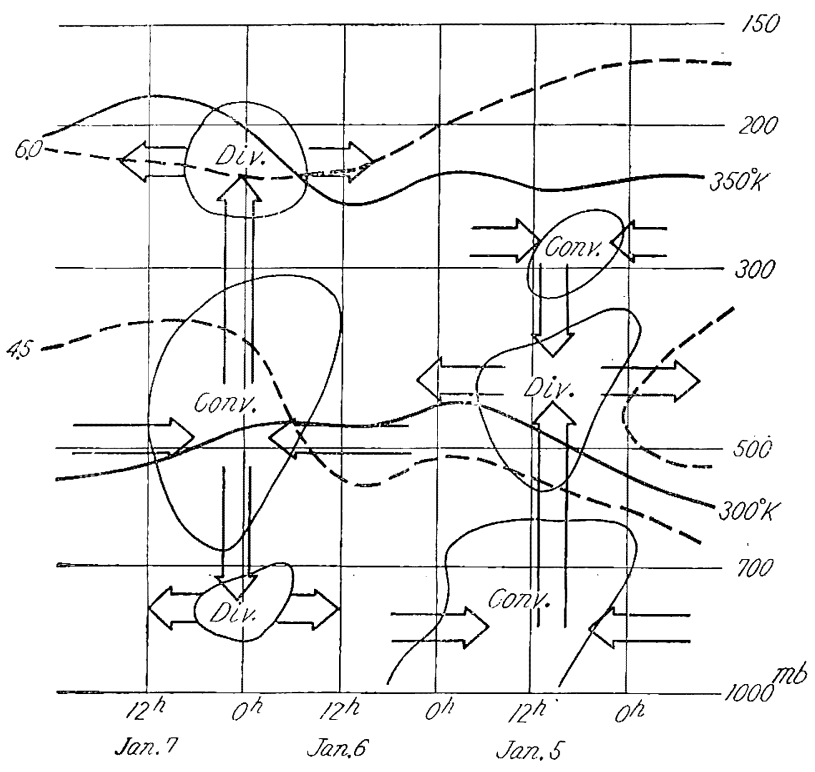

Fig. 21 Distribution of divergence and convergence areas. Thin solid lines indicates those over $\pm 10^{-5} \mathrm{sec}^{-1}$. Heavy solid lines are isentropic lines, and broken lines are iso- $\ln \left(-\frac{\partial \partial}{\partial p}\right)$ lines. Double arrows indicate schematically vertical motion. See also Fig. 15. ponds to the weak warm area and that of ascending motion to the cold area in rear of the trough. CRESSIIAN, G, P. also gave a similar figure [9].

\section{Conclusion}

The foregoing three-dimensional analysis reveals the remarkable characteristic of the trough that in upper layers it becomes very warm in front and very cold in the rear of trough and in middle layes it becomes cold in front and warm in the rear of troughs. So long as the static equilibrium of vertical stratification is correct, such a variation in temperature is not possible without the effect of divergence or convergence. After the calculation by neglecting the effect of advection which is also inevitable owing to lack of observation, we obtain the schematic model in which the divergent area in middle laye: [6] and convergent areas above and beneath it are seen in front of troughs, and convergent area in the middle layer and divergent areas above and beneath it in the rear of troughs. Thus the principal explanation of this temperature field may be sought in vertical motion. In the lower layers in front of troughs such distribution may better be considered as the structure of cyclone itself. Then iower convergence corresponds to inflow due to surface friction in the cyclone area. The superior divergence in the middle layers overcompensates for the lower convergence and causes convergence in the upper layers. The middle layer divergence should be considered as essential for cyclones. Since pressure gradient force around the cyclone center decreases upward, the ascending air ring which converges in the surface layer comes to have an excess of centrifugal force conserving its anguiar momentum. This phenomenon will be reinforced by middle layer divergence of trough [6]. Among the studies on westerly troughs, that of wave propagation has recently achieved remarkable progress. However, the variations of vertical structure in the intermediate layers should be known in order to discuss the effect on surface weather. In this paper attention is paid chiefly to the similarities between troughs, but they are different from one another as regards their effect on the 
weather. Therefore our naxt step is to investigate the characteristics proper to each trough and its relations to the lower layers.

Acknowledgment - The writers wish to thank Dr. ARAKAWA for his encouragement during the course of this investigation.

\section{References}

[1] Palmín F. and Nagiegr K. M. 1948: An Analysis of the Wind and Temperature Distribution in the Free Atmosphere over North America in a Case of Approximately Westerly Flow, Journal of Neteorology 5, p. 58.

[2] Berggrin R., Bolin B. and Rossby C.-G. 1949: An Aerological Study of Zonal Motion on the General Circulation in the Northern Hemisphere Westerlies, Journal of Neteorology, 6, p. 67.

[3] HovmöLres E., 1948: North-South Cross Section Showing Distribution of Temperature, Relative Humidity, and Wind in a Well-Marked Zonal Current over Western Europe, Journal of Meteorology, 5, p. 67.

[4] Nyberg A., 1949: An Aerological Study of Large Scale Atmospheric Disturbance, Tellus, 1, p. 44.

[5] Crfssman G. P., 1950: Variations in the Structure of the Upper Westerlies, Joumal of Isteorology, 7, p. 39.

[6] B.rerknes J. and HoLmbor 1., 1944: On the Theory of Cyclones, Journal of Meteorologg, $\mathbf{1}$, and 2.

[7] Krasner W. and London J., 1946: A Method of Forecasting Development of Tropical Cyclones, Bulletin of the Anerican Meteorological Society, 27, p. 377.

[8] Matsumoto S., 1950: A Proposition on the Advection Problem, Papers in Meteorology and Geophysics, 1, p.211.

[9] CRfssman G. P., 1948: On the Forecasting of Long Waves in the Upper Westerlies, Journal of Meteorology, 5, p. 44. 